\title{
LA DEGRADACIÓN DE LA VEGETACIÓN NATURAL EN EL CORREDOR DE ALMANSA
}

\author{
Gabino Ponce Herrero
}

\begin{abstract}
Climax vegetation like the alliance Quercion ilicis and the suballiance Quercion Valentinae specially, are determinated by climatic and edaphic conditions. Nevertheless it's been submitted under an intense deforestation from the Low Middle Ages by the man, who has been the cause of its degeneration and nearly extinction. From the middle of this century, the extensive cattle raising backward, the generalización of another combustibles, which have replace to the charcoal and wood, a closer control and interest for the forest, have made possible the disclimax regression were held up, or at last worn off. Nowadays, it could be seen a sign of degeneration.
\end{abstract}

\section{RESUMEN}

Condiciones climáticas y edáficas determinan como vegetación climática la alianza Quercion ilicis y en concreto la subalianza Quercion valentinae, no obstante, la intensa deforestación a que se ha visto sometida por el hombre desde la Baja Edad Media ha sido la causa de su degeneración y casi extinción. Desde mediados de la centuria actual, el retroceso de la ganadería extensiva, la generalización de otros combustibles, que han sustituido al carbón vegetal y la leña, y un mayor control e interés por el espacio forestal han hecho posible que la regresión disclimácica se detenga o, cuando menos, se frene, pudiéndose observar hoy día algún signo de regeneración.

\section{Bosquejo histórico}

"Al final del libro antecedente quedamos en el término de Font de la Figuera y raíces del Puerto de Almansa; subamos ahora por este puerto hacia el Norte... sálese en breve a la llanura 


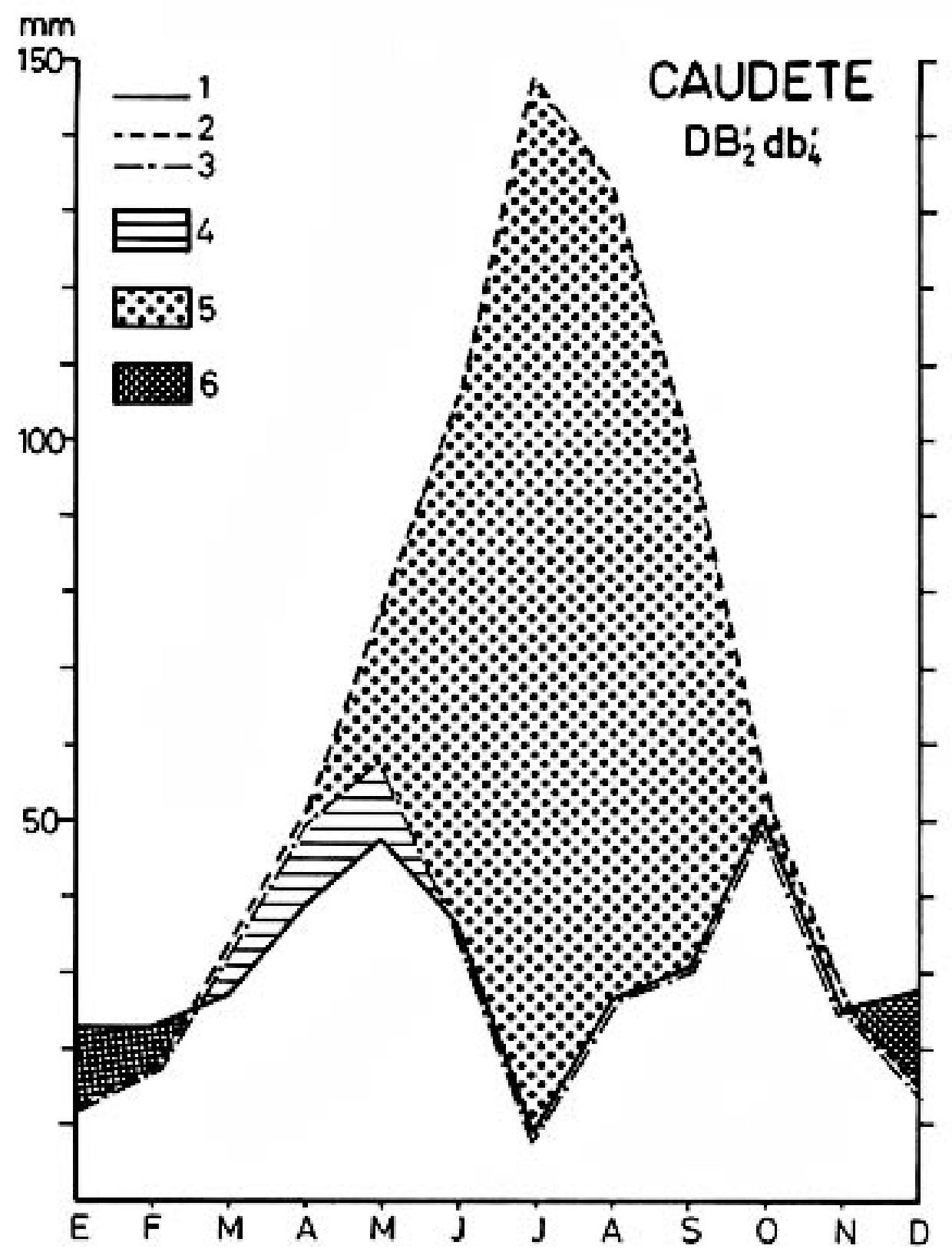

FIGURA 1: Climograma de Thomthwaite: 1. Precipitaciones; 2. Evaporación potencial (ETP); 3.Evapotranspiración real; 4. Utilización de la reserva hídrica; 5. Déficit de agua; 6.Superávit. 
y de repente desaparecen los árboles y el cultivo casi de todo punto. Por la derecha, que es aún reyno de Valencia, se ven pinares como plantados para marcar la división de reynos. El camino adelante se hallan por ambos lados tierras pobres y areniscas, donde vegetan humildes matas y algunas yerbecillas..." (1)

Con estas patéticas palabras describe Cavanilles la desoladora imagen de las tierras del Corredor en el siglo XVIII. El proceso de deforestación ha sido largo e intenso y, a grandes rasgos, puede seguirse a través de los archivos.

\subsection{El aprovechamiento ecológico de los primeros tiempos}

Hasta la baja Edad Media, debido a la pequeña densidad demográfica, la relación hombre-vegetación climax fue bastante equilibrada. El aprovechamiento forestal comienza con el proceso de repoblación tras la expulsión de los árabes, en los siglos XIII y XIV. Los señores feudales y el propio monarca concedieron en esos momentos lotes de tierra virgen para su roturación y puesta en cultivo, haciendo cesión explícita del uso de la superficie montaraz, como indica el acta en la que Alfonso X otorga los lugares de Alpera, Carcelén y Bonete a los pobladores de Almansa en 1264:

“... e que serán daqui adelante estos lugares que aquí dize por término, Alpera e Carcelén e Gonet, que los ayan con todos sus términos e con sus aguas e sus pastos e con sus montes..." (2)

En 1305 el señor de Caudete otorgó una Carta Puebla mediante la cual repartía tierras a los pobladores cristianos para que fuesen roturadas, concediendo el aprovechamiento comunal del monte, salvo una parte reservada para su uso particular:

“...el término del pinar doncell que retengo para mi” (3)

El acuerdo de hermandad firmado el 16 de abril de 1341 entre los Concejos de Almansa y Caudete sirve de ejemplo de utilización del bosque en esos momentos:

\footnotetext{
“...los de Almansa e de Alcaudete que puedan cortar lenna en qual quier de nuestros términos para su fuego e para cozer pan, del cual quier natura que sea la lenna, sin pena ninguna ...qual quier o cuales quier de nuestros vezinos podamos cortar madera para cobrir casas e para fazer arados e para todas las otras cosas que fueren menester ... salvando el pino doncel que nos los de Almansa non cortemos ... sin licencia de vos los de Alcaudete." (4)
}

\subsection{Las primeras roturaciones. Los inicios de la deforestación}

A partir de esos momentos, los núcleos de población, aldeas y caseríos, fueron los focos desde los que comenzó la roturación de los espacios forestales, que irán retrocediendo con el incremento de la presión demográfica en favor de los cultivos.

Así, el proceso se encontraba ya muy avanzado en el siglo XVI, como pone de manifiesto la Relación de Chinchilla de 1576: 


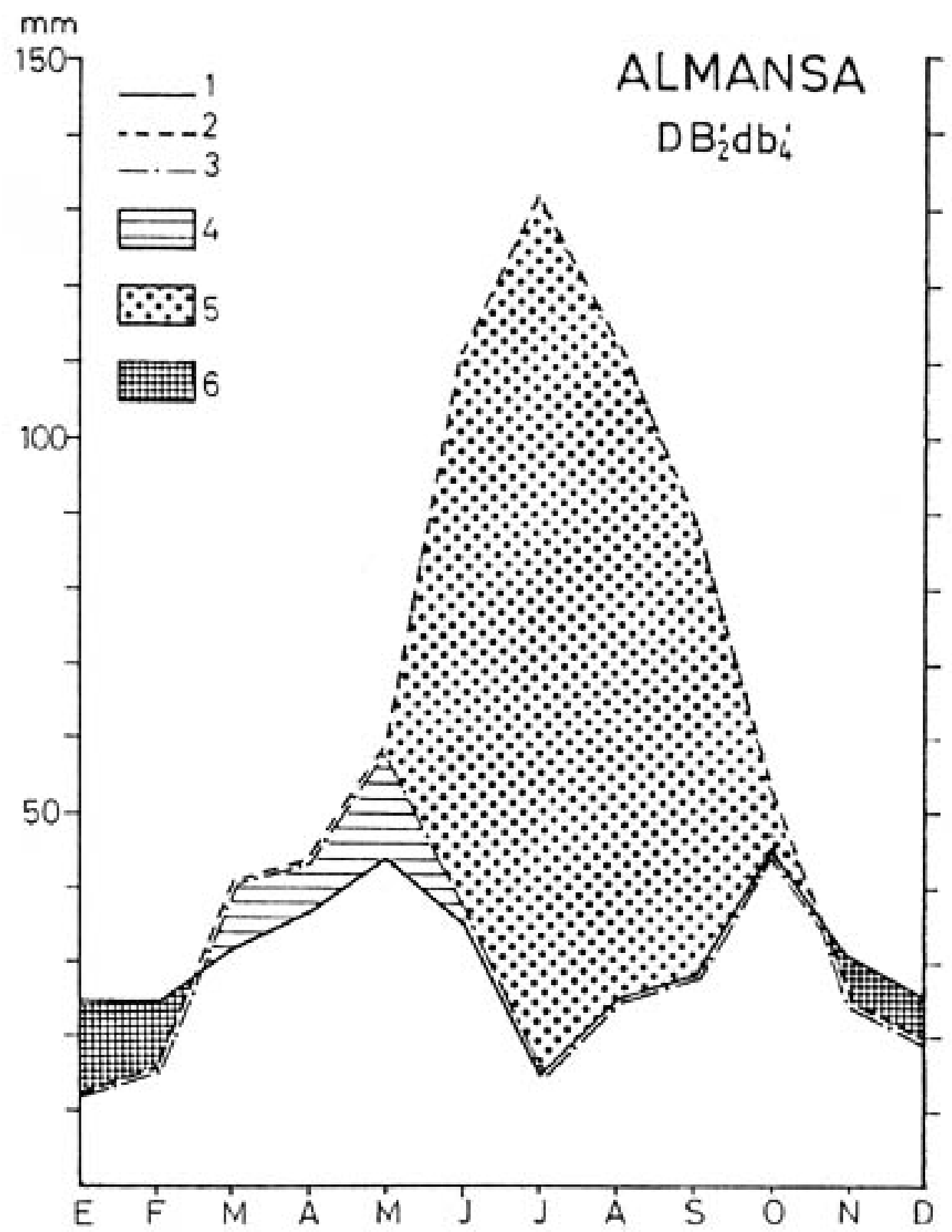

FIGURA 2: Climograma de Thornthwaite: ; 1. Precipitaciones; 2. Evapotranspiración potencial (ETP); 3. Evapotranspiración real (ETR); 4. Utilización de la reserva hídrica; 5. Déficit de agua; 6. Superávit de agua. 
“Como es tierra antigua, tiene ya muy lejos la leña" (5)

También la Relación de Montealegre de 1579 da idea de la deforestación padecida ya en esos momentos:

“...an oido dezir a sus pasados que se llamó así porque ovo en los términos della un monte de pinos carrascos y carrascas muy loçano y verde y que por eso se llamó la villa de Montealegre." (6)

Son estas Relaciones Topográficas, mandadas hacer por Felipe II en 1575, las que ofrecen la primera descripción de la flora del Corredor, dejando entrever el avanzado estado de degradación de la vegetación climácica y el acantonamiento de las especies arbóreas en los parajes más alejados y abruptos. Las especies arbustivas señaladas son tomillo (Thymus vulgaris), salvia (Salvia lavandulaefolia), aliaga (Ulex parviflorus), mata rubia (Rubia peregrina), romero (Rosmarinus officinalis), retama (Retama sphaerocarpa) y coscoja (Quercus coccifera); en las lomas roturadas, estériles para el cultivo, se desarrollaban extensos atochares o atojares (Stipa tenacissima), y en las zonas húmedas, como fondos de depresiones y lagunas estacionales, se indica la presencia de regaliz (Glycyrrhiza glabra). En el estrato arbóreo se puede intuir la mayor importancia del pino Carrasco (Pinus halepensis), seguido de la encina (Quercus ilex) y, en menor proporción, el pino doncel o piñonero (Pinus pinea). Por último, de los topónimos recogidos en las Relaciones se puede deducir la existencia de alamedas junto a los cursos fluviales, como el arroyo de Alpera o la Cañada de Pajares, y la presencia de grandes matas de hiedra (Hedera helix) en las vertientes más sombrías y húmedas de las sierras calcáreas.

En el siglo XVII continúa el empeño por roturar al máximo las tierras aptas para la agricultura. Las Ordenanzas de Montealegre, promulgadas en 1623 (7), señalan en su primer punto:

"Cualquier vecino de la villa que rompa terreno y saque tierras nuevas, puede gozar de ellas seis años".

Por todo ello, en el siglo XVIII ya eran muy reducidos los espacios forestales. Encinas y pinos habían sido talados en su mayor parte y los montes ofrecían el desolador aspecto que señala Cavanilles. La vegetación arbórea apenas era ya visible en pequeñas manchas en las umbrías más escabrosas, como la ladera septentrional del Mugrón, al pie del cerro de Meca, donde el botánico valenciano señala la existencia de bosquetes de pinos y carrascas, al tiempo que describe algunas de las plantas más notables:

“...es común el ramno humilde (Rhamnus punilus), ...las ínulas con hojas de sauce (Inula salicina), la escabiosa nueva que he llamado saxatilis (Escabiosa saxatilis), las xaras racemosas (Cistus racemosas), lampiña (Cistus laevis) y cenicienta (Cistus cinerens)."

La falta de atención para conservar las especies arbóreas de la comarca llamó ya la atención de Cavanilles:

"Hay poco cuidado en conservar los pinos que crecen en el término, cuyo número disminuye así por las quemas que maliciosamente hacen los malintencionados, o los pastores, como 
por los roces y rompimientos de terrenos nada convenientes para la agricultura... En cuanto a las carrascas, aunque pueden disponer de ellas los Alcaldes, y venderlas a beneficio del pueblo, hay menos desorden, ya sea porque se exigen diez pesos por cada una de ellas, o porque el fruto pertenece al primero del pueblo que le coge en el día señalado...”

Por último, apunta las especies más características de la serranía del norte de Alpera:

“...abunda en árboles y arbustos como carrascas, pinos, arces (Acer campestre), enebros (Juniperus oxycedrus), romeros ramnos y madroños (Arbutus unedo)."

\subsection{La competencia por el espacio forestal: el desarrollo del esparto y la desamortización} (9):

A principios del siglo XIX Miñano comenta la reducción del espacio forestal en Almansa

"Los montes producen espontáneamente muchos pinos y abundantes pastos, que mantenían en otro tiempo 25.000 cabezas de ganado lanar y cabrío; pero que en el día no pueden mantener 16.000 por la funesta manía tan general en toda España de talar y quemar estos preciosos y perennes manantiales de la riqueza pública."

En esos momentos, la gran demanda de esparto vino a potenciar el arrasamiento de los montes. El esparto, en semicultivo, ocupaba todo los espacios baldíos y los nuevos terrenos ganados tanto al monte bajo como a los cada vez más reducidos espacios arbóreos. El esparto llegó a suponer una importante fuente de ingresos, siendo vendido en localidades como Elda, donde su artesanía (alpargatería y cordelería) había alcanzado un gran desarrollo (10).

A mediados del siglo XIX Madoz vuelve a destacar el desolador aspecto de los montes de la comarca:

“...en el Mugrón... apenas queda algún pino o carrasca que recuerde la existencia de las respectivas familias que lo poblaron. Sierras de Santa Bárbara y Lácera se dan buenos pastos, leñas de mata baja y yerbas olorosas con algunas encinas y pinos... muchos cerros (en Bonete) varios de los cuales están poblados de algún monte alto”. (11)

La degradación de la vegetación climácica va pareja al desarrollo de comunidades de arbustos y matas, y Madoz recoge una amplia lista de especies. Además de esparto, romero, coscoja, mata rubia, salvia, tomillo y regalíz, especies ya señaladas en las Relaciones de 1575, indica la presencia de sabina (Juniperus phoenicea), enebro, mejorana (Mejorana hortensis), morquera (Satureja montana), espliego (Lavandula latifolia), bufalaga (Thymelea tartonraira), cicuta (Cicuta maculatum), sanguinaria (Paronychia argentea), poleo blanco (Mentha pulegium), gualda (Reseda luteola) y torbisco (Daphne gnidium), y de porte arbóreo: madroño, encina y pino.

En el marco de la desamortización, en 1861 en Almansa se habían privatizado $10.000 \mathrm{Ha}$ de romerales (matorral en general), en Alpera $14 \mathrm{Ha}$ de pinares, $800 \mathrm{Ha}$ de encinares y $150 \mathrm{Ha}$ de romerales, en Caudete $2.500 \mathrm{Ha}$ de romerales y en Bonete $2.800 \mathrm{Ha}$ de encinares (12), lo que supuso un nuevo impulso al proceso de deforestación y roturación. Así, a principios del siglo XX, el Avance del Catastro de Albacete (13) resume el estado de los montes de la comarca como expresa el cuadro adjunto. 
Cuadro I

DISTRIBUCIÓN DE LA SUPERFICIE FORESTAL EN 1909 (en Ha)

\begin{tabular}{lrrrrrr}
\hline & TOTAL & PASTOS & LEÑAS & ESPARTO & ENCINA & PINO \\
\hline Almansa & 24.577 & 6.040 & 4.909 & 5.140 & - & 8.488 \\
Alpera & 7.831 & 5.499 & 929 & - & 30 & 1.373 \\
Bonete & 5.215 & 156 & 3.284 & 1.775 & - & - \\
Caudete & 5.796 & 2.005 & 3.458 & - & - & 333 \\
Montealegre & 4.841 & 242 & - & 4.599 & - & - \\
TOTAL & 48.260 & 13.942 & 12.580 & 11.514 & 30 & 10.194 \\
\hline
\end{tabular}

Fuente: Avance Catastro Albacete, 1909.

\subsection{Los intentos de regeneración de las últimas décadas}

La tala y la roturación del monte continuaron durante la primera mitad de la centuria a la vez que se favorecía el desarrollo del espartizal (14). De esta manera, en 1959 la superficie ocupada por árboles de ribera, pinares y encinares había quedado reducida a 2.545,7 Ha en Almansa, es decir, ocupaba el 4,8\% de la superficie del término, mientras que espartizales y monte bajo se extendían por 20.861,3 Ha, esto es, por el 39,3\% de la superficie municipal (15). Es en esos momentos cuando se inician las gestiones para preservar el exiguo patrimonio forestal y regenerarlo, esgrimiendo con buen criterio el aumento de la riqueza que supondría, el mejoramiento de los pastos, la fijación de las tierras disminuyendo el riesgo de erosión, la reducción de las corrientes tumultuosas de agua y los procesos de inundación, con el consiguiente mayor almacenamiento por filtración y mejora sensible del clima local por suavización de los vientos y el aumento del grado de humedad del ambiente. Para ello se pedía una repoblación con encinas y pinos de esas 20.000 Ha de espartizal y monte bajo. En 1970 el Patrimonio Forestal del Estado (16) ya había repoblado 20.861 Ha, pero sólo de pinares (Pinus halepensis), olvidando la encina que, de esa manera, ha visto muy reducida su extensión: sólo aparecen ejemplares formando un pequeño bosquete junto con pinos carrascos en las márgenes de la Cañada del Charco, en Alpera, y ejemplares dispersos por los campos de labor, mientras que el resto del espacio forestal en la comarca se halla ocupado por formaciones de maquis, garrigas, espinares y eriales.

\section{La degradación de la vegetación clímax}

La vegetación climácica del Corredor de Almansa es la integrada en la alianza Quercion rotundifoliae, sobre los glacis y laderas de las sierras, y la propia de la alianza Populion albae en el fondo de las cubetas endorréicas, lagunas estacionales y riberas de arroyos y fuentes, como ya cita Don Juan Manuel en su Libro de la Caza (17): armajales..."

"En Alpera hay garzas, et grúas, et ánades, mas muy mala ribera de cabalgar, porque hay muchos

En la primera alianza el estrato arbóreo está formado por especies de las asociaciones 
Quercetum ilicis (encinas, madroños y sabinas) y Quercetum rotundifoliae (pino carrasco de manera principal). Los arbustos característicos del Quercetum ilicis, como el durillo (Viburnum tinus), rusco (Ruscus aculestus) o terebinto (Pistacia terebinthus) y algunas plantas trepadoras de esa asociación, como la hiedra, necesitados de un ambiente umbroso y húmedo, han ido retrocediendo con la tala del bosque de encinas. Por el contrario, el sotobosque de la asociación Quercetum rotundifoliae, heliófilo y más xerófilo, se ha favorecido de la intensa deforestación del estrato arbóreo y ha llegado a invadir, no sólo el espacio ocupado anteriormente por los pinares, sino también, el área que ocupaba la asociación Quercetum ilicis. De esta manera se ha ido llegando a un primer estado disclimácico, pasándose de un bosque denso con un estrato arbóreo predominante a un maquis dominado por arbustos.

La segunda fase de regresión se da cuando a la tala del bosque ha seguido la roturación de las tierras y su puesta en cultivo, mermando superficie al maquis. Se trata de un estado simultáneo en ocasiones a la tala del bosque, aunque normalmente le sucede. En esta fase, la degradación continúa ya que, una vez desaparecidos los árboles, será del maquis de donde se obtenga leña. Además, éste queda sometido a frecuentes incendios que lo hacen más apto para el pastoreo, ya que se esclarece la masa vegetal, se destruyen las especies no aptas para el ganado (como las plantas aromáticas y las espinas venenosas) y se obtienen brotes tiernos a la vez que se favorece la aparición de algunas gramíneas. En esta fase, en los antiguos dominios de la encina predominan los retamares y puede llegar a desarrollarse bien el pino carrasco (18), de no ser por la tala que también ha padecido. Las especies más características son la coscoja, el espino negro (Rhamnus lycioides), el enebro, la sabina reducida a un porte arbustivo, el romero, el torbisco, la bruguera (Erica multiflora), la aliaga, el alaterno (Rhamnus alaternus) y la jara (Cistus clusi) (19).

El tercer estado sobreviene con un maquis desgastado por las frecuentes roturaciones. Los arbustos alcanzan menor porte y dejan frecuentes calveros, desaparecen los árboles y se reduce el número de las especies arbustivas, apareciendo una nueva formación vegetal denominada garriga, donde destacan la coscoja, la retama, el torbisco, el romero, la salvia, el espliego, la aliaga y el esparto. En esta fase se encuentran la mayor parte de las laderas de las sierras de la comarca donde, por regeneración, es frecuente que aparezcan algunas encinas que, aun de porte arbustivo, alcanzan los dos metros de altura.

La cuarta etapa regresiva la constituyen los tomillares y los espinares. Los primeros están formados por plantas pequeñas que dejan grandes espacios sin cubrir; en la comarca están constituidos por dos alianzas: la Thymo-siderition leucanthae, con tomillo, rabo de gato (Sideritis leucanthae), esparto y torbisco como especies más características, y la Frankenion-solsolion genistoides, con el tomillo sapero (Frankenia thymifolia), escobilla (Salsola geni stoides) y albardín (Lygeum spartum). El espinar está formado por arbustos de distinto tamaño y muy esparcidos, donde predomina la aliaga, acompañada de romero, abundante esparto y algunas coscojas.

Por fin, sobre un suelo ya agotado y erosionado, aparece el último estado de regresión, donde sólo sobreviven algunas gramíneas xerófilas, sobre todo el esparto. Son los característicos atojares, o atochares, favorecidos en determinadas épocas por su interés económico. Otras gramíneas típicas son la festuca (Festuca capillifolia y Festuca scaviosa), el fenás (Brachypodium retusum), el jopillo (Stipa parviflora) y otras que forman praderas secas o pseudo-estepas. 


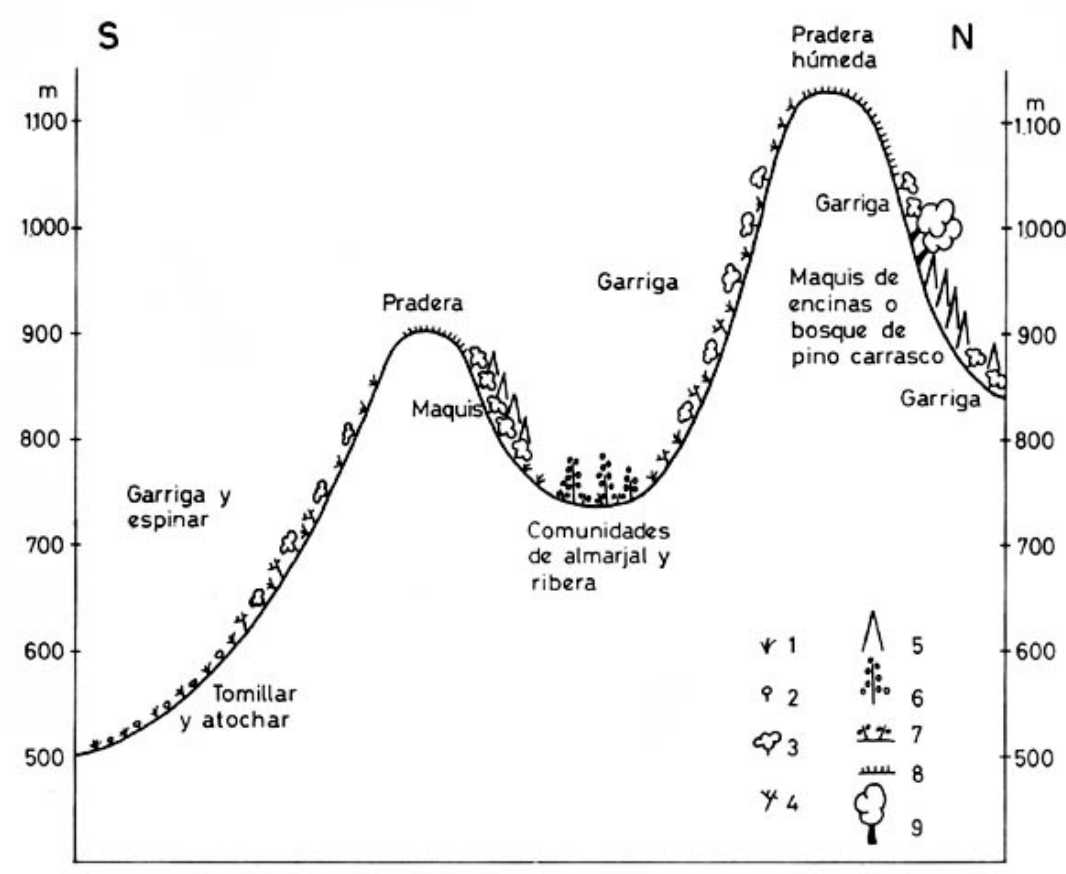

FIGURA 3: Cliserie de la vegetación natural en el Corredor de Almansa. 1.Esparto; 2. Tomillares (thymo siderition siucantae y frankenio solsolium genistoides); 3. Arbustos: enebro, romero, coscoja, etc. (rosmarino ericion); 4. Espinos: espino negro; 5. Pino carrasco (pinus halepensis); 6. Al. populium albae; 7. Al. salicomion fruticosae; 8. Pradera húmeda (thero-brachipodion); 9. Encina (quercus ilex).

\section{El reparto actual de la vegetación}

Las distintas comunidades vegetales de la comarca se encuentran en uno u otro de los estado de regresión apuntados según diferentes aspectos como son su exposición a la acción del hombre (agricultura, ganadería, extracción de leña y carboneo), la naturaleza del suelo y el grado de humedad. Algunos rodales de vegetación, en las zonas más marginales, presentan en la actualidad un estrato arbóreo formado por encinas y pinos, con un sotobosque importante, que podrían encuadrarse en la fase final del primer estado de regresión comentado; junto a ellos, grandes superficies incultas, pequeñas colinas y terrenos quebrados ofrecen la imagen característica de la pseudo-estepa y los atochares. Así, la vegetación actual del Corredor de Almansa puede enmarcarse en una serie de estados condicionados por la altitud (que favorece un mayor grado de humedad por el aumento sensible de las precipitaciones y por 
el descenso térmico) y la orientación y exposición, que marcan grandes contrastes entre umbrías, con densos tapices vegetales donde pueden llegar a predominar los árboles, y solanas caracterizadas por un matorral bajo. En este sentido, Rivas Goday (20) ha introducido el término grado de vegetación para distinguir las diferentes especies climácicas de cada zona concreta. Aplicando su clasificación a la comarca pueden distinguirse dos grados fundamentales:

- Grado mediterráneo. Caracterizado por especies siempre verdes, adaptadas a la aridez (con protección pilosa, espinas, etc.), que se desarrolla en las tierras más bajas -por debajo de los 700-800 m- donde las temperaturas son elevadas en verano y suaves en invierno. En la comarca, con una altitud comprendida entre 500 y $1.200 \mathrm{~m}$, se da sobre las laderas de los principales relieves, en los terrenos incultos de los fondos de valle y en las pequeñas sierras y colinas de Montealegre y Caudete.

La vegetación climácica está formada por las especies de la asociación Quercetum rotundifoliae, pero su área de difusión se encuentra en competencia directa con los terrenos de cultivo, de ahí que alcance poca extensión en la actualidad. Las especies arbóreas, encina y pino carrasco, casi han desaparecido en este ámbito. Tan sólo las márgenes de la Cañada del Charco, en Alpera, y en el paraje de Botas, en Almansa, es posible ver la encina con porte arbóreo, formando pequeños bosquetes sobre los materiales del Trías y cuaternarios en la finca El Carrascal y en ejemplares aislados sobre la ladera occidental del Mugrón y en Botas, esparcidos sobre el terrazgo cerealícola.

Junto a la encina, y en los lugares en que ésta no aparece, se desarrolla una cubierta de garriga, encuadrable en el tercer estado de la regresión disclimácica. Está formada por especies de la alianza Rosmarino-ericion, con coscoja, retama, enebro, romero, bruguera, aliaga, diversas jaras, salvia, espliego y esparto.

Sobre los materiales del Trías, donde el substrato es rico en sulfato cálcico (yesos y margas yesíferas), el Rosmarino-ericion es sustituido por plantas fruticosas de pequeño tamaño de la asociación Gypsophiletalia, y en concreto por la alianza Thymo-teucrion verticillati, donde se encuentran el haliantemo yesero (Helianthemum squamatum), la boja (Anthyllis cytisoides), el tomillo negro (Artemisa barrelieri), la escobilla, el esparto y el barceo o albardín como especies más características. Esta alianza se extiende sobre la banda triásica entre Alpera y Montealegre, por el paraje de Las Cabezuelas en Almansa y por las proximidades del Salero de Villena en Caudete.

En las zonas endorréicas localizadas sobre suelos salinos, con abundante humedad edáfica durante todo el año, aparecen especies de la alianza Salicornion fruticosae, como el salicornio (Salicornia fruticosa), la Gypsophila perfoliata y su variante tormentosa, la acelga salvaje (Limonium ovalifolium) y el junco (Holoschoenus vulgaris), que se desarrolla también junto a fuentes y acequias. Forman unos herbazales densos que, en la actualidad, sólo aparecen en las inmediaciones de Casa Bianca y Casa Zornoza en el paraje de Los Cuchillos, en la Hoya Rasa y en la Cañada del Agua Salada, todos en término de Montealegre.

En las antiguas lagunas -hoy desecadas-, formadas sobre materiales cuaternarios, y en los cursos de agua, al pie de fuentes y acequias, la vegetación dominante pertenecía a la alianza Populion albae, formada por especies de hoja caduca como el chopo (Populus alba), olmo (Ulmus campestris) y sauce (Salix fragilis), y un sotobosque de exigencias mesófilas donde destaca el regalíz. En la actualidad apenas quedan restos de esta comunidad, sometida a una intensa tala para aprovechar su madera y porque los suelos que ocupa (aluvio 


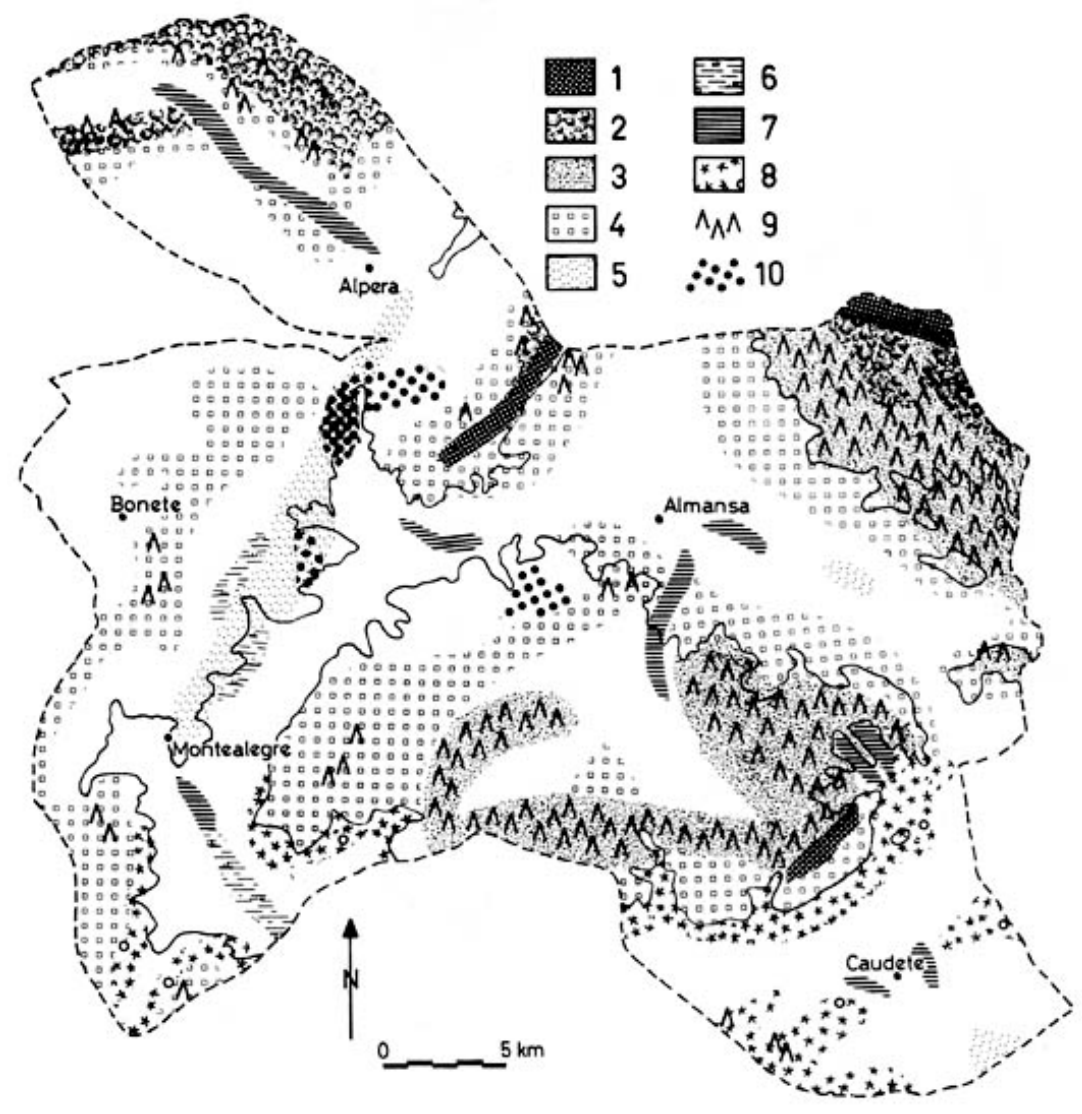

FIGURA 4. Distribución de la vegetación natural en el Corredor de Almansa: 1. Al. Thero-branchipodion; 2. As. Quercetum ilicis; 3. As. Quercetum rotumdifoliae; 4. Al. Rosmarino ericcion; 5. Thymo-teucrion verticillati; 6. Al. Salicomion fruticosae; 7. Al. Populion albae; 8. Al. Thymosideriton leucantae y Frankenio-solsolion; 9. Pinus halepensis; 10. Quercus ilex.

coluviales) son los más ricos de la comarca para el aprovechamiento agrícola. Así, sólo aparece formando galerías en algunas ramblas (en las más húmedas) como en la Cañada de Pajares, en puntos de la Cañada del Charco, en la Rambla de los Molinos y en el Barranco del Agua Verde.

Por debajo de los 600-700 m la alianza Rosmarino-ericion deja paso a la alianza Thymosiderition leucanthae sobre suelos pedregosos y poco profundos, con tomillo, rabo de gato, esparto, jaguarzo (Helianthemum salicifolium), torbisco y otras; y a la alianza Frankenion- 
solsolion genistoides sobre suelos pardo calizos profundos (21), con tomillo, escobilla y albardín como especies más características. Se trata de plantas más termófilas desarrolladas sobre suelos muy degradados y en un ambiente de gran aridez. Aparecen en los valles meridionales de Montealegre y Caudete, sobre las márgenes de los cultivos y caminos y en espacios baldíos.

- Grado Montano-submediterráneo. Se desarrolla por encima de los 800-900 m, con la asociación Quercetum ilicis como vegetación climácica. Ocupa pues la parte más elevada de las laderas de las sierras de la comarca: Santa Bárbara, el Mugrón, Serranía de Almansa, Punta de Gira Valencia y la alineación el Malefatón-la Muela-el Bosque. En la zona de cumbres, la delgada capa de suelo -litosuelo- limita su desarrollo y es sustituida por especies de la clase Thero-brachypodietea.

El estrato arbóreo está compuesto por la encina y el pino carrasco fundamentalmente, aunque aparecen ejemplares aislados de fresno (Fraxinos ornus) y madroño en los lugares más umbríos. La encina se encuentra totalmente degradada; los ejemplares de porte arbóreo son mínimos y las masas de Quercus ilex sólo forman grandes arbustos (de hasta dos metros de altura) asociados de manera general a la coscoja y a la vegetación propia del maquis: sabinas, enebros y romeros en las zonas más húmedas, y romero y espino negro en las más áridas (sierras de Montealegre y Caudete).

Los pinares también han sufrido una intensa degradación hasta casi desaparecer de la comarca. En la actualidad, gracias a la repoblación de los años sesenta, aparecen formando importantes masas en la Serranía de Almansa, en la alineación Cerro de la Cruz-Cerro de la Bandera-Cerro de la Tea, en la umbría de Santa Bárbara y en los Altos de Jodar-las Ardacheras-Loma de los Caballos, mientras que en el resto del Corredor sólo aparecen agrupaciones de algunos ejemplares.

Debido a la regresión de la asociación Quercetum ilicis, es ésta la zona de mayor desarrollo de la Quercetum rotundifoliae, con sus formaciones típicas de maquis, donde predomina el matorral alto con algunos árboles, y la garriga. Esta asociación tiene en la actualidad un gran desarrollo en las muelas cretácicas del norte de Alpera, donde el estrato arbóreo sólo queda reflejado en la toponímia: El Bosque, la Muela, el Malefatón, Punta de Gira Valencia, en las sierras del Pinaroso, de la Cueva Alta y de la Cuerda en Montealegre y, en general, en las estribaciones de los grandes conjuntos serranos del Corredor.

En altura se degrada el maquis, que deja paso a la garriga, con arbustos de menor porte, y ésta, en las umbrías y cimas de las sierras, donde es mayor la humedad y menor la capa de suelo (no apto como soporte de la vegetación más exigente), se caracteriza por la formación de praderas con especies de la alianza Thero brachypodion. Es el área donde la hiedra alcanza portes espectaculares, acompañada de la Euphorbia characias, planta venenosa para el ganado, característica de los encinares degradados (22). En las solanas no llega a darse el maquis, la vegetación se encuentra en el estadio disclimácico de transición entre la garriga y el espinar y, en altura, por encima de los $800 \mathrm{~m}$, es el esparto el mejor adaptado (asciende hasta los $1.100 \mathrm{~m}$ en la solana de Santa Bárbara). A esa altitud aparecen en menor proporción el romero, enebro y matas de coscoja aisladas que no rebasan los $60 \mathrm{~cm}$ de altura.

\section{Conclusiones}

Las optimas condiciones para el desarrollo de una agricultura de secano extensivo (suelo 
y clima) han provocado el retroceso de la vegetación climática y su degradación, según un proceso histórico de presión antrópica debido a las continuas roturaciones, a la explotación forestal (leña y carboneo), al desarrollo de la ganadería y la competencia del espartizal en siglos pasados y, en general, al escaso interés prestado al patrimonio forestal.

Las etapas regresivas padecidas por el estrato arbóreo de la alianza Quercion rotundifoliae facilitaron primero el desarrollo del matorral y las praderas pseudo-esteparias, favorecidas en ocasiones por el interés económico de los atochares (materia prima de la primera artesanía alpargatera de la zona), y después, con las labores de repoblación, ha sido el pino el beneficiado, ocupando la mayor parte de la superficie no productiva, de manera que la encina sólo aparece, por regeneración, en las márgenes de suelos poco aptos para la agricultura, formando pequeñas agrupaciones, y dispersa sobre los campos de cereales, como un destacado elemento que rompe la monotonía del paisaje, con una función heredada: la de dar sombra al pastor y a su ganado que aprovecha las rastrojeras en el periodo canicular.

\section{NOTAS BIBLIOGRÁFICAS}

1 CAVANILLES, A.J., Observaciones sobre la historia natural, geografía, agricultura, población y frutos del Reyno de Valencia, Imp. Real, Madrid, 1795-1797, t. II, p. 1

2 PRETEL MARÍN, A., Don Juan Manuel. Señor de la llanura, 1EA.-CSIC., Albacete, 1982, 296 pp.

3 PRETEL MARÍN, A., Almansa medieval. Una villa del señorío de Villena en los siglos XIII, XIV y XV, Ayto. Almansa, Albacete, 1981, 271 pp., apend. doc. III

4 CARTA PUEBLA DE CAUDETE, otorgada por Juan García de Lisón en 6-III-1305. Vid SOLER GARCÍA, J.M., La Relación de Villena de 1575, IEA., Alicante, 1969, pp. 211-214

5 PRETEL MARÍN, A., 1982, ob. cit., apend. doc. 34, p. 283

6 Biblioteca del Real Monasterio del Escorial: Relación de Montealegre, 20-III-1579, A-483, fols. 618-624; Relación de Chinchilla, 30-VII-1576, A-456, fols. 424-460 v. (incluye Bonete); Relación de Alpera, 17-XII-1575, t. 5, J-I-16, fols. 519-523 v.

7 ZUAZO Y PALACIOS, J., La Villa de Montealegre y su Cerro de los Santos, Madrid, 1915, 222 pp., p. 168

8 CAVANILLES, A.J., 1797, ob. cit., t. II, pp. 8-9

9 MIÑANO, A., Diccionario geográfico-estadístico de España y Portugal, Madrid, 1826, t. I, p. 155

10 NAVARRO PASTOR, A., Historia de Elda, CAPA., Alicante, 1981, t. 1, 379 pp., p. 325

11 MADOZ, P., Diccionario geográfico estadístico histórico de España y sus posesiones de ultramar, Madrid, 1846, t. II, pp. 68 y ss.

12 COMISIÓN PROVINCIAL DE ESTADÍSTICA, Anuario estadístico de la provincia de Albacete, CPE., Albacete, 1861, 327 pp., pp. 258-263

13 DIRECCIÓN GENERAL IMP. Y RENT., Memoria resumen de los trabajos de Avance Catastral llevados a cabo en la provincia de Albacete, Ministerio de Hacienda, Alicante, 1909, 465 pp.

14 FERNÁNDEZ PALAZÓN, G., El esparto en España. Estudio geográfico y económico, 1971, Tesis doctoral, Univ. Murcia. Vid SÁNCHEZ SÁNCHEZ, J., Geografia de Albacete, IEA.-CSIC., Albacete, t. II, p. 95: actividad que alcanzó gran desarrollo en la provincia en la etapa de autarquía de la posguerra. CÁMARA AGRARIA LOCAL DE ALMANSA, Informe, de la Delegación Provincial de Sindicatos, Almansa, 1959, 6 fols. mecanograf.

16 Organismo que, en 1971, daría origen al ICONA

17 PRETEL MARÍN, A., 1982, ob. cit., p. 114, nota biblio. 337

18 BOLOS I CAPDEVILA, O., "El sols i la vegetació dels Paisos Catalans", Geografía física dels 
Paísos Catalans, Barcelona, 1979, pp. 131 y ss.

19 CLIMENT I GINER, D., Les nostres plantes, I.E. Juan Gil-Albert, Alicante, 1985, 312 pp., p. 92

20 RIGUAL MAGALLON, A., Flora y vegetación de la provincia de Alicante, IEA., Alicante, 1972, 403 pp., p. 23

21 MORALES GIL, A., El altiplano de Jumilla-Yecla, Dpto. Geografía, Univ. Murcia, Murcia, 1972,467 pp., p. 104

22 CLIMENT I GINER, D., 1985, ob. cit., p. 59 